American Journal of Applied Sciences 7 (8): 1043-1046, 2010

ISSN 1546-9239

(C) 2010 Science Publications

\title{
Extraction of $\mathrm{Ca}(\mathrm{II})$ and $\mathrm{Mg}(\mathrm{II})$ from Hydrochloric Acid Solutions by $\mathrm{N}, \mathrm{N}$-Dioctyl-1-Octanamine in Methyl Isobutyl Ketone
}

\author{
${ }^{1}$ Fatmir Faiku, ${ }^{2}$ Arben I. Haziri and ${ }^{3}$ Haxhere Faiku \\ ${ }^{1}$ Section of Analytical and Environmental Chemistry, \\ ${ }^{2}$ Section of Organic Chemistry and Biochemistry, \\ Department of Chemistry, Faculty of Natural Sciences, \\ University of Pristina, Mother Teresa Street 5, 10000 Prishtine, Kosova \\ ${ }^{3}$ Department of Natural Science, Association Loyola Gymnasium, \\ Ring Rout, 20000 Prizren, Kosova
}

\begin{abstract}
Problem statement: Amines as organic molecules are able to form complexes with metals ions and this is the reason why we can use them to extract metals ions from hydrometallurgical solutions. Approach: Based on that, we have investigated the extraction of Calcium and Magnesium with $\mathrm{N}, \mathrm{N}$-dioctyl-1-octammine from the mixture of elements prepared in artificial manner. We investigated the influence of $\mathrm{HCl}$ concentration and salts $\left(\mathrm{NaCl}, \mathrm{NaI}\right.$ and $\mathrm{CH}_{3} \mathrm{COONa}$ ) concentration in extraction of two elements (Calcium and Magnesium) from water solutions. All extractions were done from $\mathrm{HCl}$ water solutions with $\mathrm{c}=3,6$ and $9 \mathrm{~mol} \mathrm{~L}^{-1}$ and in presence of $\mathrm{NaCl}, \mathrm{NaI}$ and $\mathrm{CH}_{3} \mathrm{COONa}$ salts, which we prepared in different concentrations. Results: Extraction of Calcium from $\mathrm{NaCl}$ solution move from $50-75 \%$, from $\mathrm{NaI}$ solution $0-90 \%$ and from $\mathrm{CH}_{3} \mathrm{COONa}$ solution $37-81 \%$. Extraction of Magnesium from $\mathrm{NaCl}$ solution move from $0-10 \%$. In solution of $\mathrm{NaI}$ we can not extract the Magnesium and from $\mathrm{CH}_{3} \mathrm{COONa}$ solution the extraction of magnesium moves from $0-30 \%$. Conclusion: As optimal condition to separate Calcium from Magnesium is the extraction of Calcium from $\mathrm{HCl}$ solution with concentration $9 \mathrm{~mol} \mathrm{~L}^{-1}$ in presence of $\mathrm{NaI}$ with concentration of $60 \mathrm{~g} \mathrm{~L}^{-1}$. Using these condition $90 \%$ of Calcium was in organic phase and all of magnesium remains in water phase.
\end{abstract}

Key words: Extraction, calcium, magnesium, N,N-dioctyl-1-octamine, organic phase, aqueous phase

\section{INTRODUCTION}

Extraction of metals with organic bases with large molecular masse is forced in the last years (Cox et al., 2004). The importance of metals extraction, with organic bases, is in the selectivity of organic compounds for anionic metal complexes, obtained in reversible way in water solution, which are more stable than simple anions (Sengupra and Yizhak, 2001).

Systems that we will discuss here, are some extracted species formed as result of interactions between a neutral species or anionic metallic species in water solution and salts of any organic bases or their cation in organic or in water phase. This kind of extraction is known as associated ionic extraction, where a cationic part is alkyl ammonium,-arsenium orphosphonium cation (McClellan et al., 1974).

Faiku et al. (2009) have investigated the extraction of Calcium and Magnesium with mixture of N,N- dioctyl-1-octanammine and N,N-dioctyl-1-octan ammonium chloride and only with N,N-dioctyl-1-octan ammonium chloride. They have found that all changing factors have influence in extraction percentage of calcium and magnesium in organic phase.

Kimura (1960) has done the extraction of some metals including Calcium and Magnesium, from $\mathrm{HCl}$ solution with concentration $0.01 \mathrm{~mol} \mathrm{~L}^{-1}, 0.1 \mathrm{~mol} \mathrm{~L}^{-1}$ and $1 \mathrm{~mol} \mathrm{~L}^{-1}$ with di-(2-Ethylhexyl) phosphoric acid (50\% in toluene). He found that Calcium was extracted $11 \%$ from solution of $\mathrm{HCl}$ with concentration $0.1 \mathrm{~mol}$ $\mathrm{L}^{-1}$, while Magnesium was extracted $36 \%$ from $\mathrm{HCl}$ solution with concentration $0.01 \mathrm{moL} \mathrm{L} \mathrm{L}^{-1}$.

Organic molecules as alamine 336 (Filiz, 2007; Sayar and Filz, 2007; 2009), aliquat 336 (Atanassova et al., 2002; El-Nadi et al., 2009), are able to form complexes with metals ions and for that we can use them to extract metals ions from hydrometallurgical solutions.

Corresponding Author: Fatmir Faiku, Section of Analytical and Environmental Chemistry, Department of Chemistry, Faculty of Natural Sciences, University of Prishtina, Mother Tereza Street 5, 10000 Prishtine, Kosova 
Based on that we have investigated the extraction of Calcium and Magnesium with N,N-dioctyl-1octanamine from mixture of elements prepared in artificial way.

\section{MATERIALS AND METHODS}

In this study we used reagents with p.a. purities from which we have prepared solutions with dissolving the appropriate amount of $\mathrm{CaCl}_{2} \times 6 \mathrm{H}_{2} \mathrm{O}$ and $\mathrm{MgCl}_{2}$ in distillate water. Water solutions of Calcium and Magnesium with metal concentration of $1 \mathrm{~g} \mathrm{~L}^{-1}$ were prepared using $\mathrm{CaCl}_{2} \times 6 \mathrm{H}_{2} \mathrm{O}$ and $\mathrm{MgCl}_{2}$. As organic phase we used $10 \%$ solution of N,N-dioctyl-1octanammine in methyl isobutyl ketone. Methyl isobutyl ketone was used as carrier solvent for organic bases. This solvent was mixed totally with N,N-dioctyl1-octanamine. The structural formula of N,N-dioctyl-1octanamine is shown in Fig. 1.

$\mathrm{N}, \mathrm{N}$-dioctyl-1-octanamine can form complex salts, with a large number of metals, which are not soluble in water, but are soluble in organic phases. To determine the $\mathrm{Ca}$ and $\mathrm{Mg}$ quantities in water solutions, we used absorber spectrophotometer Buck Scientific Model 200A.

For extraction, we used $10 \%$ of N,N-dioctyl-1octanamine in methyl isobutyl ketone. All extraction were done from $\mathrm{HCl}$ water solutions with concentrations 3, 6 and $9 \mathrm{~mol} \mathrm{~L}^{-1}$ and in presence of $\mathrm{NaCl}, \mathrm{NaI}$ and $\mathrm{CH}_{3} \mathrm{COONa}$ salts. Also the water solutions of $\mathrm{NaCl}, \mathrm{NaI}$ and $\mathrm{CH}_{3} \mathrm{COONa}$ salts, we have prepared in different concentrations. Extraction of Calcium and Magnesium was done with separator funnel of $150 \mathrm{~mL}$.

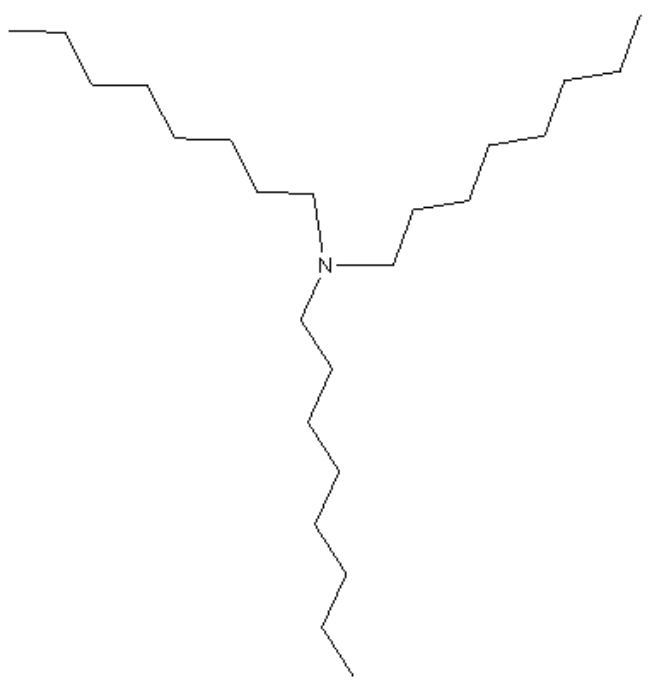

Fig. 1: Structure of N,N-dioctyl-1-octanammine
We used a series of nine separator funnels with standard mixture solutions and series of nine separator funnels without standard, where are present just water solution of acid and salt. About $10 \mathrm{~mL}$ of water model and $10 \mathrm{~mL}$ of organic solution were mixed in separator funnel twice for one minute. Mixture was left to stay during nights and then we have separated organic phase from water phase. Water phase was used to determine elements Calcium and Magnesium) that were present (remain) in it.

\section{RESULTS}

In Table 1-3 are results obtained experimentally for extraction of elements as function of acid and salts concentrations. For extraction of elements in organic phase we took three experiments with three different salts concentrations which all of them are nine systems. From these systems we have done extraction.

Table 1: Extraction of calcium and magnesium with N,N-dioctyl-1octanamine in presence of $\mathrm{NaCl}$

\begin{tabular}{lllr}
\hline $\mathrm{c}(\mathrm{HCl}) \mathrm{mol}^{-1} \mathrm{~L}^{-1}$ & $\gamma(\mathrm{NaCl}) \mathrm{g}^{-1} \mathrm{~L}^{-1}$ & $\mathrm{Ca}$ & $\mathrm{Mg}$ \\
\hline 3 & 20 & 50.0 & 5.2 \\
6 & 20 & 65.2 & 7.1 \\
9 & 20 & 70.1 & 10.0 \\
3 & 40 & 60.6 & 3.3 \\
6 & 40 & 63.2 & 5.1 \\
9 & 40 & 68.4 & 8.0 \\
3 & 60 & 66.1 & - \\
6 & 60 & 69.2 & - \\
9 & 60 & 75.0 & 2.1 \\
\hline
\end{tabular}

Table 2: Extraction of calcium and magnesium with N,N-dioctyl-1octanamine in presence of $\mathrm{NaI}$

\begin{tabular}{llll}
\hline $\mathrm{c}(\mathrm{HCl}) \mathrm{mol}^{-1} \mathrm{~L}^{-1}$ & $\gamma(\mathrm{NaI}) \mathrm{g}^{-1} \mathrm{~L}^{-1}$ & $\mathrm{Ca}$ & $\mathrm{Mg}$ \\
\hline 3 & 20 & - & - \\
6 & 20 & 22.4 & - \\
9 & 20 & 88.4 & - \\
3 & 40 & 32.5 & - \\
6 & 40 & 71.6 & - \\
9 & 40 & 82.0 & - \\
3 & 60 & 40.2 & - \\
6 & 60 & 84.1 & - \\
9 & 60 & 90.0 & - \\
\hline
\end{tabular}

Table 3: Extraction of calcium and magnesium with N,N-dioctyl-1octanamine in presence of $\mathrm{NaAc}$

\begin{tabular}{lllc}
\hline $\mathrm{c}(\mathrm{HCl}) \mathrm{mol}^{-1} \mathrm{~L}^{-1}$ & $\gamma(\mathrm{NaAc}) \mathrm{g}^{-1} \mathrm{~L}^{-1}$ & $\mathrm{Ca}$ & $\mathrm{Mg}$ \\
\hline 3 & 20 & 37.0 & - \\
6 & 20 & 63.5 & 5.5 \\
9 & 20 & 81.0 & 30.0 \\
3 & 40 & 41.7 & - \\
6 & 40 & 62.5 & - \\
9 & 40 & 68.0 & 6.0 \\
3 & 60 & 43.4 & - \\
6 & 60 & 62.6 & - \\
9 & 60 & 71.1 & 12.2 \\
\hline
\end{tabular}




\section{DISCUSSION}

Extraction of Calcium from acidic solution containing $\mathrm{NaCl}$, is shown in Fig. $2 \mathrm{a}-\mathrm{c} . \mathrm{NaCl}$ and $\mathrm{HCl}$ concentrations have a little influence in extraction percentage of Calcium.

Extraction of Calcium from acidic solution that contains NaI, is presented in Fig. 3a-c. The presence of $\mathrm{NaI}$ has high influence in extraction percentage of Calcium. From Fig. 3a we can see that in $\mathrm{HCl}$ solution with concentration of $3 \mathrm{~mol} \mathrm{~L}^{-1}$, extraction of Calcium is zero and with increasing of acidities extraction of Calcium will increase continually till $88.4 \%$ (in solution of $\left.9 \mathrm{~mol} \mathrm{~L}^{-1} \mathrm{HCl}\right)$. So, $\mathrm{HCl}$ and $\mathrm{NaI}$ concentrations have higher influence in extraction of Calcium.

Extraction curve of Calcium obtained from sodium acetate solution are almost same. Extraction percentage of Calcium from sodium acetate solutions will increase with increasing of $\mathrm{HCl}$ concentration. The influence of sodium acetate concentration in extraction of Calcium is lower (Fig. 4-c).

In all cases the extraction percentage of Magnesium is lower or is zero (Fig. 2a-c; 3a-c; 4a-c). One exception we found that extraction of Magnesium is $30 \%$ when extraction was done in $\mathrm{HCl}$ solution with concentration $9 \mathrm{~mol} \mathrm{~L}^{-1}$ and in presence of sodium acetate with concentration $20 \mathrm{~g} \mathrm{~L}^{-1}$ (Fig. 4a).

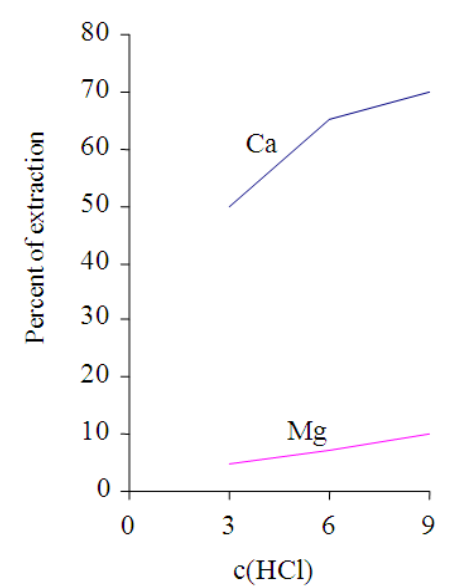

(a)

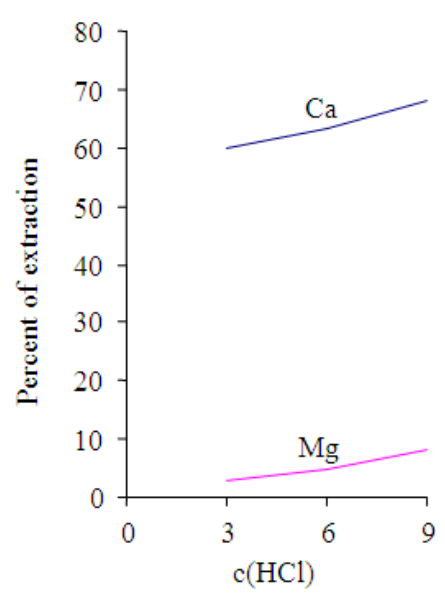

(b)

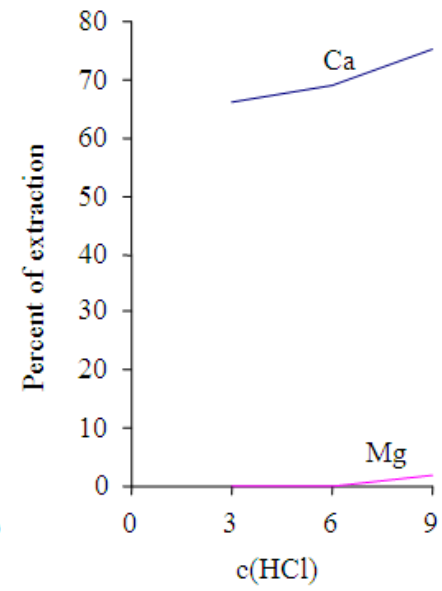

(c)

Fig. 2: Extraction curves, of elements with $\mathrm{N}, \mathrm{N}$-dioctyl-1-octanamine shown, as function of $\mathrm{HCl}$ and $\mathrm{NaCl}$ concentrations: (a) $\gamma(\mathrm{NaCl})=20 \mathrm{~g} \mathrm{~L}^{-1}$; (b) $\gamma(\mathrm{NaCl})=40 \mathrm{~g} \mathrm{~L}^{-1}$; (c) $\gamma(\mathrm{NaCl})=60 \mathrm{~g} \mathrm{~L}^{-1}$

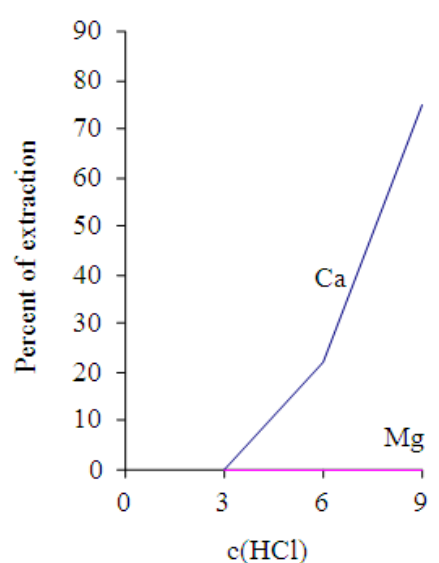

(a)

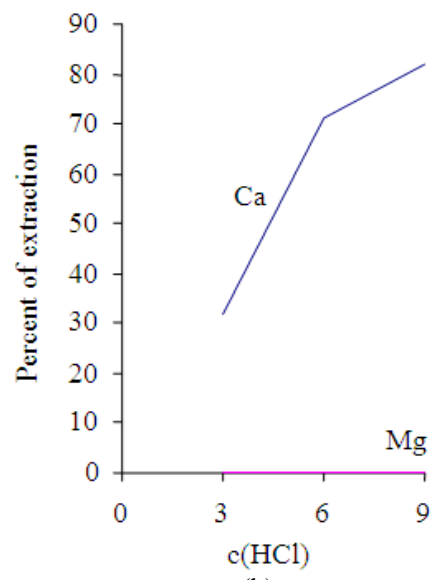

(b)

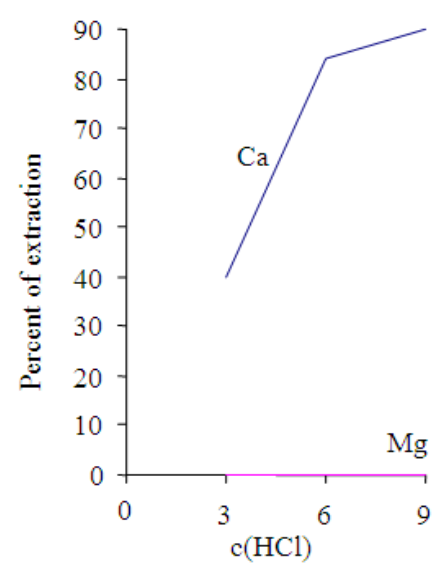

(c)

Fig. 3: Extraction curves, of elements with N,N-dioctyl-1-octanamine shown, as function of $\mathrm{HCl}$ and $\mathrm{NaI}$ concentrations: (a) $\gamma(\mathrm{NaI})=20 \mathrm{~g} \mathrm{~L}^{-1}$; (b) $\gamma(\mathrm{NaI})=40 \mathrm{~g} \mathrm{~L}^{-1}$; (c) $\gamma(\mathrm{NaI})=60 \mathrm{~g} \mathrm{~L}^{-1}$ 
Am. J. Applied Sci., 7 (8): 1043-1046, 2010

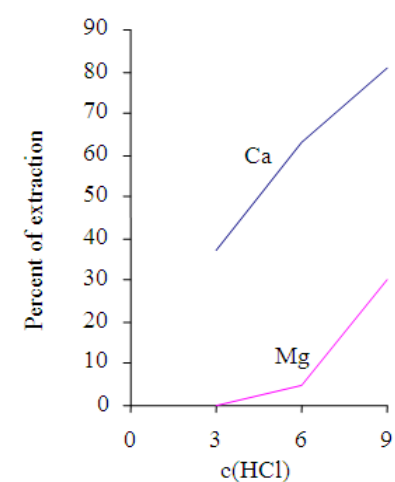

(a)

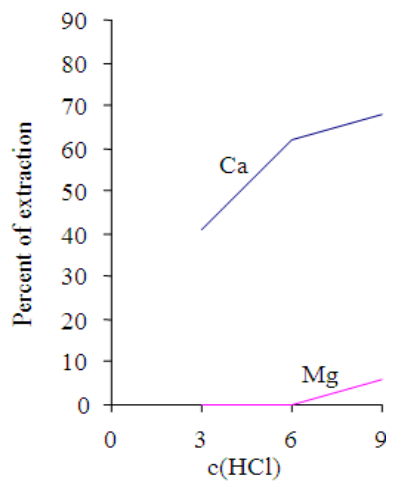

(b)

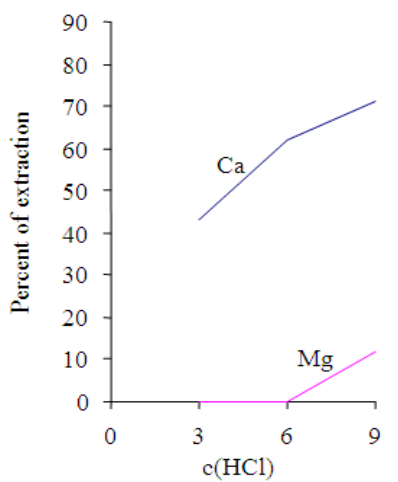

(c)

Fig. 4: Extraction curves of elements with $\mathrm{N}, \mathrm{N}$-dioctyl-1-octanamine shown, as function of $\mathrm{HCl}$ and $\mathrm{NaAc}$ concentrations: (a) $\gamma(\mathrm{NaAc})=20 \mathrm{~g} \mathrm{~L}^{-1}$; (b) $\gamma(\mathrm{NaAc})=40 \mathrm{~g} \mathrm{~L}^{-1}$; (c) $\gamma(\mathrm{NaAc})=60 \mathrm{~g} \mathrm{~L}^{-1}$

\section{CONCLUSION}

From our results we can conclude:

- Extraction of Calcium from $\mathrm{NaCl}$ move from 50$75 \%$, from $\mathrm{NaI}$ solution $0-90 \%$ and from $\mathrm{CH}_{3} \mathrm{COONa}$ solution $37-81 \%$

- Extraction of Mangesium from $\mathrm{NaCl}$ solution move from $0-10 \%$. In solution of $\mathrm{NaI}$ we can not extract the magnesium and from $\mathrm{CH}_{3} \mathrm{COONa}$ solution the percentage extraction of magnesium moves from $0-30 \%$

- Extraction percentage of Calcium and Magnesium increase with increasing of $\mathrm{HCl}$ concentration

- As optimal condition to separate Calcium from Magnesium is the extraction of Calcium from $\mathrm{HCl}$ solution with concentration $9 \mathrm{~mol} \mathrm{~L}^{-1}$ in presence of NaI with concentration of $60 \mathrm{~g} \mathrm{~L}^{-1}$. Using these condition $90 \%$ of Calcium was in organic phase and all of magnesium remains in water phase

\section{ACNOWLEDGMENT}

The authors acknowledge the financial support received from the University of Prishtina, Kosova.

\section{REFERENCES}

Atanassova, M., V. Jordanov and I. Dukov, 2002. Effect of the quaternary ammonium salt Aliquat 336 on the solvent extraction of lanthanoid (III) ions with thenoyltrofluoroacetone. Hydrometallurgy, 63: 41-47. DOI: 10.1016/S0304386X(01)00199-2

Cox, M., C. Musikas and G.R. Chopin, 2004. Principles and Practices of Solvent Extraction. 2nd Edn., Marcel Dekker, New York, ISBN: 0824750532, pp: 760.
El-Nadi, Y., N. Awwad and A. Nayl, 2009. A comparative study of vanadium extraction by Aliquat-336 from acidic and alkaline media with application to spent catalyst. Int. J. Mineral Process., 92: 115-120. DOI: 10.1016/jminpro.2009.03.005

Faiku, F., H. Faiku, A. Haziri, M. Paçarizi and F. Gashi et al., 2009. Extraction of the calcium and magnesium with N,N-dioctyl-1-octanamine. Proceeding of the 2nd Symposium Chemistry and Environment, Sept. 16-19, HDCG, Montenegro, pp: 139-139.

Filiz, M., 2007. Extraction of Mn(II) from aqueous hydrochloric acid solutions into Alamine 336-mxylene system. Hydrometallurgy, 87: 58-62. DOI: 10.1016/j.hydromet.2007.02.001

Kimura, K., 1960. Inorganic extraction studies on the system between bis (2-ethylhexyl)-orthophosphoric acid and hydrochloric acid (I). Bull. Chem. Soc. Jap., 46: 306-308. DOI: 10.1021/ac60338a009

McClellan, B.E., M.K. Meredith, R. Parmelee and J.P. Beck, 1974. Solvent extraction studies of chromium (II1) with tri-n-octylamine. Anal. Chem., 46: 306-308. DOI: 10.1021/ac60338a009

Sayar, N. and M. Filiz, 2009. Extraction of Co(II) and $\mathrm{Ni}(\mathrm{II})$ from concentrated $\mathrm{HCl}$ solutions using Alamine 336. Hydrometallurgy, 96: 148-153. DOI: 10.1016/j.hydromet.2008.09.005

Sayar, N. and M. Filz, 2007. Extraction of Zn(II) from aqueous hydrochloric acid solutions into Alamine 336-m-xylene systems. Modeling considerations to predict optimum operational conditions. Hydrometallurgy, $\quad 86$ : 27-36. DOI: 10.1016/j.hydromet.2006.10.005

Sengupra, A. and M. Yizhak, 2001. Ion Exchange and Solvent Extraction. 1st Edn., CRC Publisher, USA., ISBN: 10: 0824706013, pp: 504. 